\title{
Honing action competence in sustainable development: what happens in classrooms matters
}

\author{
Wanda Sass $^{1}$ (I) . Sven De Maeyer ${ }^{1}$ (D) Jelle Boeve-de Pauw ${ }^{1}$ (D) $\cdot$ Peter Van Petegem ${ }^{1}$ (D)
}

Received: 26 May 2021 / Accepted: 5 February 2022 / Published online: 25 February 2022

(c) The Author(s), under exclusive licence to Springer Nature B.V. 2022

\begin{abstract}
In effectiveness literature, voices are rising to embrace learning contents beyond mathematics, science, and language. Meanwhile, international policy documents such as the United Nations 2019 Climate Action Summit Report point at the importance of action for sustainable development for establishing acceptable life conditions for current and future generations. Therefore, a candidate learning outcome for broadening effectiveness research's scope is action competence in sustainable development (ACiSD), which consists of the relevant knowledge, willingness, capacity expectations, and outcome expectancy regarding actions for sustainable development. In order to initiate adding ACiSD as a learning outcome to effectiveness research, the current study contributed to establishing that formal education plays a part in changes in students' ACiSD. Firstly, we studied how much variance in ACiSD can be attributed to what happens in classrooms. Secondly, we looked into how class groups' and early adolescent students' ACiSD changed after one school year. Following recommendations for rigour in effectiveness research, we performed multilevel analyses on survey data (question one: $n=1398$; question two: $n=633$ ). Our evidence showed that $11 \%$ of variance in ACiSD was attributable to what happens in classrooms with explained variance in the subconstructs ranging between 7.2 and 14.2\%. Furthermore, individual students as well as class groups showed higher ACiSD scores when comparing measurements at beginning and end of one school year. We conclude that the classroom level matters to changes in ACiSD within early adolescents. Further research can now look into how and to which extent teachers' educational approaches affect these changes.
\end{abstract}

Keywords Action competence - Sustainable behaviour - Sustainable development · Action competence in sustainable development questionnaire (ACiSD-Q) - Class group differences in ACiSD · Multilevel analyses

Wanda Sass

wanda.sass@uantwerpen.be

Extended author information available on the last page of the article 


\section{Introduction}

Research into the effects of current and future climate change scenarios on living conditions (e.g. Javadinejad, Dara, \& Jafary, 2020; Kerich, 2020; Oo, Zin, \& Kyi, 2020) guides our attention to the need for sustainable development. Along with the research community, also international policy makers keep underscoring the importance of sustainable development in order to secure acceptable living conditions for current and future generations (European Commission, 2019; United Nations, 2019). These policy recommendations build onto the 17 Sustainable Development Goals (United Nations, 2015), which aim at working towards sustainable development, which was defined as a process of mutually interacting environmental, social, and socio-economic perspectives. Educational efforts at all levels are paramount if we are to promote environmental and sustainable behaviour that would allow to take on the challenges involved (Amézaga et al., 2021; Minelgaitė \& Liobikienè, 2021; Sekhar \& Raina, 2021). In order to monitor these efforts, measurement of learning outcomes is crucial (Amézaga et al., 2021; UNESCO, 2017). Still, educational effectiveness research has mainly focused on cognitive learning outcomes of single subjects such as mathematics, (native) language, and sciences. Various voices have suggested broadening this scope by also including affective and social educational goals (Muijs, 2006; Muijs et al., 2014; Reynolds, Chapman, et al., 2016; Townsend et al., 2016). In line with Reynolds et al.'s (2016) call to make educational effectiveness research more relevant to practitioners and policymakers, Kelly and Clarke (2016) advocated focusing on sustainable development issues. In order to find adequate solutions to such issues and act upon them, relevant knowledge, awareness, and competence are needed (Amoah \& Addoah, 2021; Arı \& Y1lmaz, 2017; Milfont, 2012; Yilmaz \& Can, 2020). Action competence in sustainable development (ACiSD) consists of the relevant knowledge, willingness, capacity expectations, and outcome expectancy regarding actions for sustainable development (Jensen, 2000; Mogensen \& Schnack, 2010; Sass et al., 2020). As such, it is a desired learning outcome of education for sustainable development, which aims to prepare students for current and future sustainability challenges (Breiting \& Mogensen, 1999). Consequently, ACiSD can be considered a suitable outcome variable for measuring effectiveness of educational efforts that focus on sustainable development. Theoretic claims have been made about action-oriented ESD as a promising approach to teaching, i.e. at class group level, that would foster ACiSD (Mogensen \& Schnack, 2010; Sinakou et al., 2019). The rationale was that through this democratic and action-oriented approach to teaching students would learn about and for sustainable development, and as agents of change (Sinakou et al., 2019; Varela-Losada et al., 2016). In other words, by allowing students to participate in decisionmaking processes through deliberative discussions about real-world controversial issues, they would build sustainability competences such as ACiSD (Ottander \& Simon, 2021). However, studies providing evidence that confirms these theoretic assumptions are lacking. Effectiveness research has found differences between schools as well as between class groups in learning outcomes such as mathematics, language, and science (Reynolds et al., 2014; Scheerens, 2016). Moreover, the importance of the classroom level for explaining variance in learning outcomes is now widely accepted, as it was found to explain more variance than the school level (Chapman, Muijs, et al., 2016; Chapman, Reynolds, et al., 2016; Hattie, 2009; Scheerens, 2016). This level does not only consist of 'manipulations' by the teacher, but is also affected by 'an ecology' (Scheerens, 2016, p. 4) that includes factors such as whether there is an open and safe atmosphere where mistakes are considered opportunities for learning, the kind of interactions between students, and between 
teacher and students (Hattie, 2009; Scheerens, 2016). Consequently, before teacher effectiveness regarding implementation of an educational approach thought to promote ACiSD can be studied, there is a need to establish whether changes in learning outcomes such as ACiSD can be attributed to this overall classroom level. It is the aim of this study to fill this research gap. We will look into the extent to which the classroom level matters to changes in overall ACiSD within early adolescents as well as to their conceptual knowledge, willingness, capacity expectations, and outcome expectancy regarding actions for sustainable development. In this, we are especially interested in early adolescents, i.e. 10-14-year-olds, because that is when civic involvement is developed (Smetana et al., 2006). As sustainability knowledge and awareness enhances future policy makers' and managers' engagement for developing a sustainable future (Sekhar \& Raina, 2021), this adds to the importance of the stage in life when civic involvement is developed. The following research questions (RQ) guided our research:

RQ1: To what extent does early adolescents' ACiSD differ with the class group they belong to?

RQ2: To what extent do changes in early adolescent students' ACiSD during a school year depend on the class group they belong to?

Answers to these two research questions will contribute to the literature by paving the way for ACiSD to be included as a learning outcome in educational effectiveness research. Educational practitioners will be informed about the effects on students' ACiSD development of what happens in class groups. Finally, policymakers may find evidence to justify the attention paid to ACiSD development in formal education.

\section{Literature review}

In what follows, we will explore existing literature concerning (1) differences in explained variance regarding learning contents such as mathematics, science, and (native) language, and (2) the concept of ACiSD as a learning outcome of education for sustainable development.

\subsection{Differences in explained variance regarding learning contents mathematics, science, and (native) language}

In the field of educational effectiveness research, reviews of the literature have confirmed that factors at the classroom level explain variance in learning outcomes to a much larger extent than between-school factors. This led to consensus about the importance of class groups (Hattie, 2009). Moreover, especially in early adolescence, students may turn towards their peers for support and social modelling (Hattie, 2009; Smetana et al., 2006), which adds to the importance of class groups. Depending on the review consulted, educational effectiveness research reports on different effect sizes of by classroom and teacher level explained variance in overall learning outcomes, varying from an average of 10-20 per cent (Muijs, 2006) over about 15-18 per cent (Scheerens, 2016) to 25 per cent of total variance (Reynolds, Teddlie, et al., 2016). In this, differences between learning content areas have to be acknowledged (Chapman, Reynolds et al., 2016. Overall, variation in both school and teacher effectiveness seems to be higher 
in mathematics and science as compared to language and non-cognitive learning outcomes (Chapman, Muijs, et al., 2016; Hattie, 2009; Sammons, Davis, \& Gray, 2016; Reynolds et al., 2014). A possible explanation may lie in that parents are more likely to influence their children's language acquisition and spend less time on doing mathematics or science with them at home (Hattie, 2009; Scheerens, 2016; Reynolds et al., 2014; Sammons, Davis, \& Gray, 2016). Furthermore, non-cognitive learning outcomes may be less prominently focused on in school curricula, whereas students may be more engaged in non-academic learning when spending time outside the school (Reynolds et al., 2014).

In sum, educational effectiveness research reveals that 10-25 per cent of variance in average overall learning can be attributed to school and classroom levels. School and classroom effects tend to be higher for outcomes that are typically less focused on outside school, such as mathematics and sciences. Effects on language and non-cognitive outcomes are typically lower, as students are possibly more exposed to those in the homes and other contexts outside school.

\subsection{Action competence in sustainable development (ACiSD)}

As outlined earlier, a desired outcome of education for sustainable development is action competence, which involves acquisition and creation of the relevant conceptual knowledge of action possibilities, willingness to contribute, and self-efficacy. The latter comprises confidence in one's capacity for change (capacity expectations) and in the effect (outcome expectancy) of the action (Breiting, Hedegaard, Mogensen, Nielsen, \& Schnack, 2009; Jensen, 2000; Jensen \& Schnack, 2006; Sass et al., 2020). When considering action competence in sustainable development (ACiSD), the action aims to contribute to solving sustainability issues. The United Nations defined sustainable development as consisting of interrelated aspects that include environmental and climatic (planet), social (people), economic (prosperity), and peace concerns, which all individuals, local communities, and participating nations engage to take on in partnership. This engagement aims to build a better life for current and future generations, which explicitly involves respecting the planet's finite resources and addressing concerns about dwindling diversity both in the natural and cultural world (United Nations, 2015). Consequently, as shown in Fig. 1, ACiSD encompasses students' conceptual knowledge of sustainable development action possibilities, willingness to contribute to sustainable development, confidence in one's capacities for change towards a more sustainable future, and confidence that the action taken will contribute to sustainable development (Sass et al., 2020).

In the following sections, we will first describe the current study's methodological aspects of ethical considerations and bias, the instruments used to measure the participating students' ACiSD at beginning and end of one school year, the samples used for answering the two research questions, and the rigorous analytical procedure we applied. In the results section, we provide a detailed presentation of the evidence we found. Finally, we summarise our findings and integrate them in the current literature in the conclusion and discussion section. 


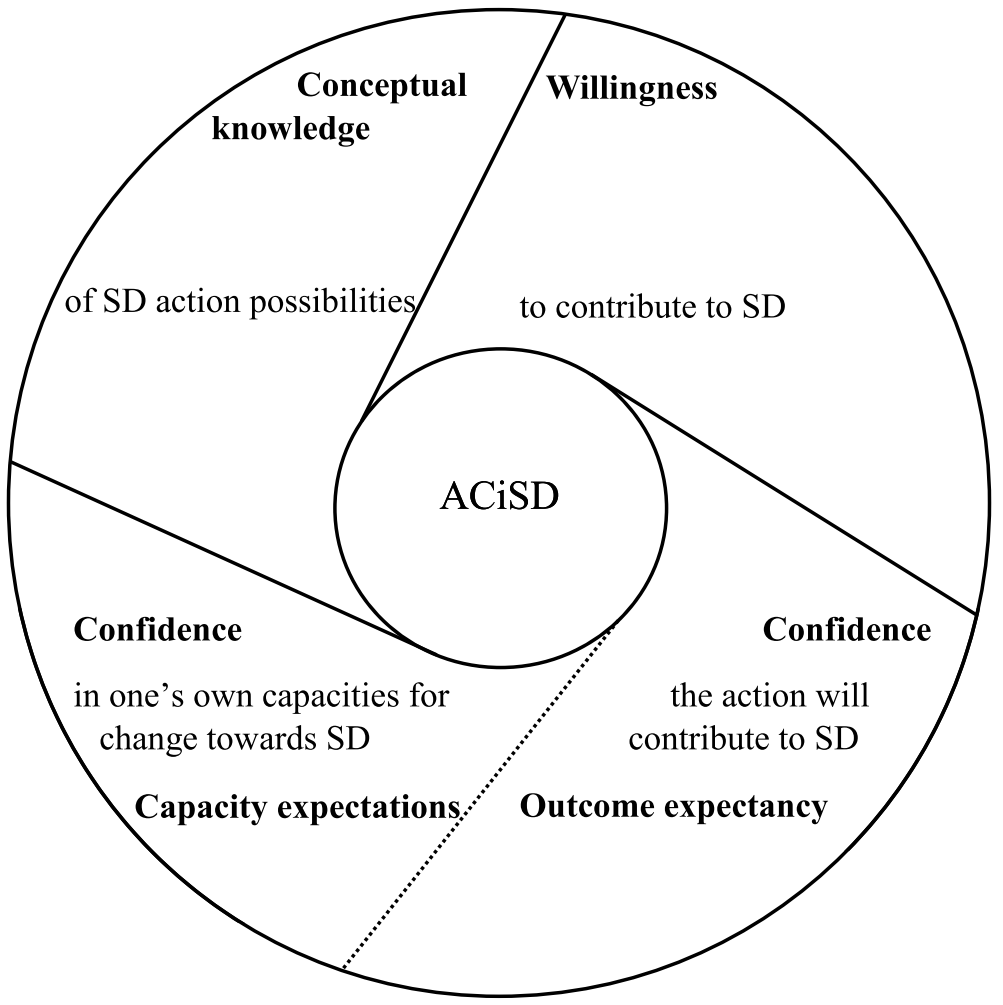

Fig. 1 Core features of ACiSD (after Sass et al., 2020) Note: $S D=$ sustainable development

\section{Methods}

\subsection{Ethical considerations and bias}

Participants' answers were only used in analyses after thoroughly informed active consent was given by both the participants and one of the parents. The teachers involved in the data collections were instructed to make clear to all participants that we were interested in them, in what they thought and felt about actions for sustainable development, and not in what they thought adults would like them to think or feel. Furthermore, all participants were guaranteed anonymity in order to avoid social desirability bias, and informed that their participation was voluntary. Participants were asked not to communicate with each other while completing the questionnaires to prevent peer pressure (Scott, 2008).

\subsection{Measures}

We measured students' action competence in sustainable development using the 36-item Action Competence in Sustainable Development Questionnaire (ACiSD-Q; Sass, Boevede Pauw, De Maeyer, \& Van Petegem (2021), which was developed for our target population of 10- to 14-year-olds (see Fig. 2). The ACiSD-Q is a validated instrument that consists of 


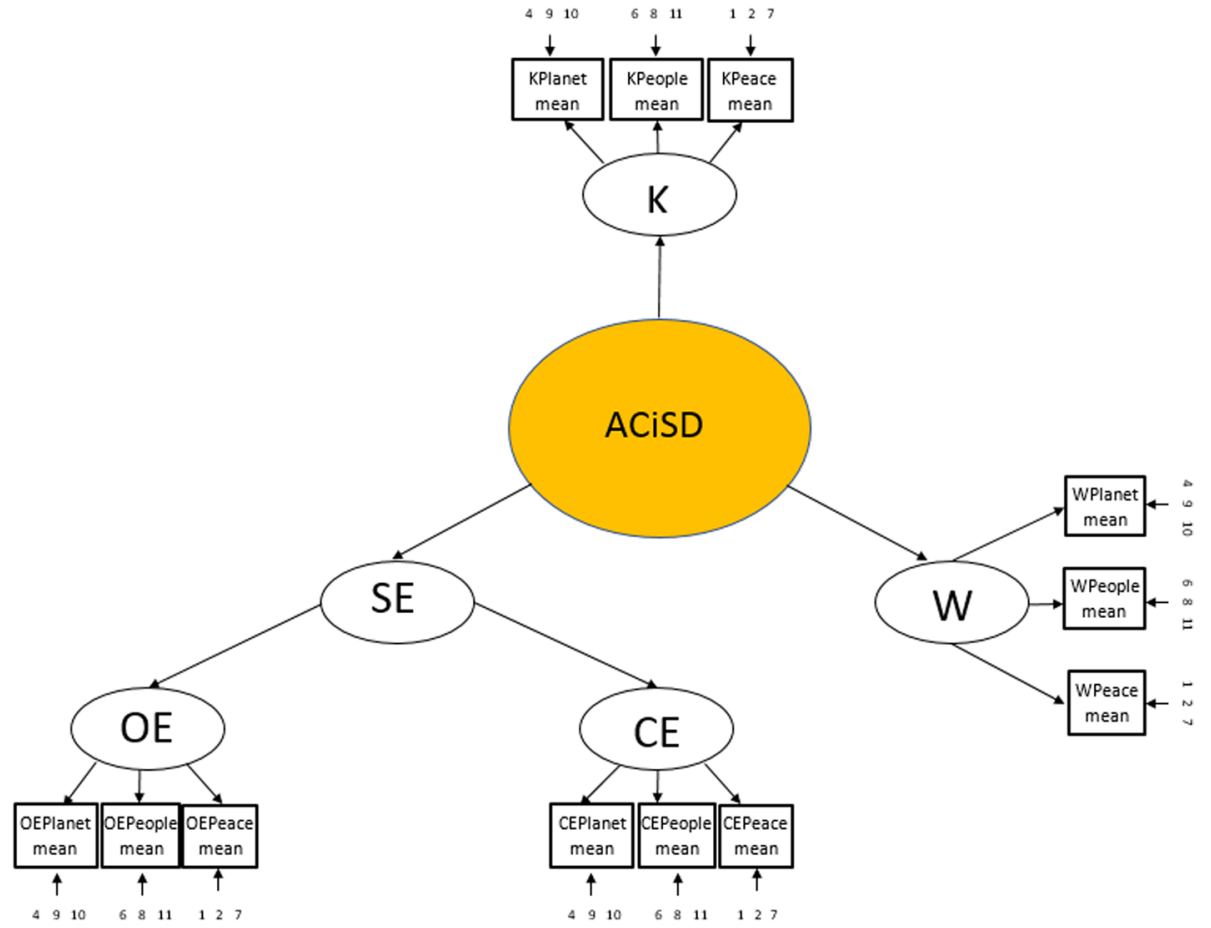

Fig. 2 The ACiSD-Q consists of latent variables self-efficacy (SE), conceptual knowledge (K), and willingness (W). Self-efficacy consists of two subconstructs: capacity expectations (CE) and outcome expectancy (OE). The first-order variables consist of items categorised into environmental (planet: items 4, 9, and 10), social (people: items 6, 8, and 11), and peace aspects (peace: items 1,2, and 7) of sustainable development. (After Sass, Boeve-de Pauw et al., 2021)

Table 1 Description of samples for research questions one and two

\begin{tabular}{lll}
\hline & RQ1 & RQ2 \\
\hline Schools: $n$ & 40 & 29 \\
Class groups & 98 & 57 \\
Grades & $5,6,8$ & $5,6,7,8$ \\
Participants: $n$ & 1398 & 633 \\
Mean age & 11.12 & 11.83 \\
Gender & & \\
Male & $751(54 \%)$ & $327(52 \%)$ \\
Female & $620(44 \%)$ & $305(48 \%)$ \\
Undisclosed & $27(2 \%)$ & $1(<0.2 \%)$ \\
Level & & 244 \\
Primary & 1060 & 389 \\
Secondary & 338 & \\
\hline
\end{tabular}

four statements regarding nine items (also see Table 5 in the Appendix). The four statements tap into action competence subconcepts conceptual knowledge, willingness to perform, and two self-efficacy measures, i.e. capacity expectations and outcome expectancy 
regarding actions for sustainable development. The nine items cover actions for sustainable development with three items for environmental (planet: items 4, 9, and 10), social (people: items 6, 8, and 11), and peace (items 1,2, and 7) actions, respectively. For the full statements and questions, we refer to Table 5 in the Appendix which uses the same item numbers and subconstruct codes (K, W, SE, CE, and OE) as Fig. 2.

Respondents express (dis)agreement with the statements through a 5-point Likert scale that includes a neutral centre $(1=$ completely disagree, $3=$ don't agree/don't disagree, $5=$ completely agree for conceptual knowledge, willingness, and outcome expectancy; $1=$ certainly not, $2=\mathrm{I}$ don't think so, $3=$ maybe, $4=\mathrm{I}$ think so, $5=$ certainly for capacity expectations). This measurement instrument was developed in cooperation with the target population, i.e. early adolescents (aged 10-14). The nine items that cover the sustainable development categories of environmental, social, and peace issues were drawn from early adolescents' own suggestions for feasible actions in a pre-study. (For a more detailed description, we refer to Sass, Quintelier et al., 2021 and Sass, Boeve-de Pauw et al., 2021)

\subsection{Samples}

This research is part of a larger project, Valorising Integrated and Action-Oriented Education for Sustainable Development (VALIES). The aim of this project is to study the critical success factors and barriers for bringing integrated and action-oriented education for sustainable development into schools in Flanders, Belgium. For the current research, data were collected through convenience sampling at beginning and end of school year 2019-2020.

The ACiSD questionnaire was administered to 1398 participants in grades five, six, and eight by teachers in the classroom during one class period at the start of the school year (M0) for answering RQ1. Seventh graders were excluded, because this is the first year in secondary education, when students typically change schools. Consequently, grade seven students had only been part of their class group for 1 month. From these 1398 participants, complemented with seventh graders, 633 filled the questionnaire both at the beginning (M0) and end of the school year (M1) for answering RQ2 as shown in Fig. 3. The participating schools could opt either for administration on paper (79.5\% of participants at M0) or online (91\% of participants at M1). Due to circumstances related to the COVID-19 pandemic, most students filled the questionnaires online at home at the end of the school year. They received the instructions given orally in class at M0 and in writing for M1.

All teachers (and for the second measurement of RQ2 also the responsible adults at home) received the same instructions to enhance reliability. They could give technical assistance, but were asked not to help respondents with interpreting items or questions. Efforts were made to reduce missingness. The paper questionnaires highlighted the need for answering all questions and provided information on how many answers should have

$n$

RQ1

RQ2

1398 (grades 5, 6, and 8)

663 (from $1398+$ grade 7)

663 (grades 5 to 8 )

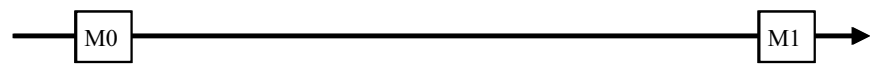

Fig. 3 Overview of samples used for answering research question one (M0; grades 5, 6, and 8: $n=1398$ ) and research question two (M0 and M1; grades 5 to 8 including grade $7: n=663$ ) 
been given on each page of the questionnaire so that participants could eliminate any accidental oversights. Regarding the online questionnaires, we opted for forced responses.

As data for the first research question were collected at the start of school year 2019-2020 and many students change schools between primary and secondary, students in grade seven (the first year of secondary) were excluded from the sample used for RQ1 (To what extent does early adolescents' ACiSD differ with the class group they belong to?). This resulted in a sample of 1398 participants in grades five, six, and eight (mean age 11.12) across 98 class groups in 40 schools that covered all five provinces of Flanders. In this sample that consisted of 1060 primary and 338 secondary school students, 751 participants were male, 620 female, and 27 preferred not to disclose their gender, as given in Table 1 which provides an overview of the samples used for both research questions.

For the second research question (To what extent do changes in early adolescent students' ACiSD during a school year depend on the class group they belong to?), participants in grade 7 were also included, as this involved analyses of two different measurements, at the beginning (M0) and end (M1) of school year 2019-2020. Consequently, all students had been part of their class group for at least one complete school year at the time of the second measurement. This sample of 633 participants (mean age 11.83), of which 327 were male, 305 female, and one did not disclose their gender, included 244 primary and 389 secondary school students across 57 class groups in 29 different schools across the five Flemish provinces. Table 1 gives an overview of all samples used for answering both research questions.

\subsection{Analytic procedure}

In what follows, we first describe the multilevel analyses that addressed students' responses to the ACiSD-Q at the start of the school year in order to establish to what extent the classroom level affects students' ACiSD (RQ1). We then describe multilevel analyses performed to capture possible changes in their responses across two different moments, i.e. at the beginning and end of one school year (RQ2). Multilevel models were implemented for both research questions to account for the fact that observations are not independent (Hox, Moerbeek, \& van de Schoot, 2017). As there is evidence in the literature that gender and educational level may affect students' concerns regarding sustainable development (Arı \& Y1lmaz, 2017; Lee et al., 2019; Olsson et al., 2019) and participants to our study included boys and girls in primary and secondary school, we also controlled for gender and educational level (i.e. primary or secondary) to find out how much variance in ACiSD and its subconstructs (conceptual knowledge, willingness, capacity expectations, and outcome expectancy) remained attributable to the classroom level. Additionally, we provide descriptive statistics (means and standard deviations) for ACiSD and its subconstructs in Table 6 in the Appendix.

All analyses were performed using RStudio 4.0.2. For answering the first research question, we used R Packages lme4 (Bates, Mächler, Bolker, \& Walker, 2015) for fitting and analysing multilevel models, and lmerTest (Kuznetsova, Brockhoff, \& Christensen, 2017) for calculating $p$-values. For answering the second research question, we used R-package 'nlme' (Pinheiro et al., 2014) for estimations, and ggplot2 (Wickham, 2016) for visualisation of results.

We provide fixed effects and variance estimates for both research questions. 


\subsubsection{Analytic procedure for answering RQ1}

As we collected data of individual students that were part of class groups, our data were treated as nested with students at level $1(n=1398)$ and the class groups to which they pertained at level 2 ( $n=98)$. We estimated several models: (1) overall ACiSD; (2) conceptual knowledge of action possibilities; (3) willingness to perform actions for sustainable development; (4) overall self-efficacy and self-efficacy subconstructs; (5) capacity expectations; and (6) outcome expectancy regarding the actions for sustainable development. Variance estimates were used for calculating intraclass correlation coefficients (ICC) to provide the proportion of variance in ACiSD attributable to the classroom level. We compared model fit of the different models and controlled for gender and educational level (primary or secondary education).

\subsubsection{Analytic procedure for answering RQ2}

Our data can be viewed as multilevel multivariate data where responses at different time points (M0, M1) are treated as different variables (Rabe-Hesketh \& Skrondal, 2012) that are modelled simultaneously. The two responses (at the beginning and end of the school year; level 1) are nested within individual students (level 2; $n=633$ ), who are part of individual class groups (level $3 ; n=57$ ). For answering the second research question, we modelled two intercepts (being a mean score at each moment, i.e. M0 and M1), two variances between students and two variances between class groups (one per moment so the model considers that the variance between students and class groups can be a function of the moment in the procedure). We performed likelihood ratio tests to compare models in which we allowed for differences in variance of change (from M0 to M1) between individuals with models in which also differences in change between class groups were included. Again, all analyses were conducted separately for the overall ACiSD as well as for subconstructs conceptual knowledge, willingness, overall self-efficacy, and self-efficacy subconstructs capacity expectations, and outcome expectancy.

\section{Results}

In this section, we first discuss the results of the multilevel analyses that address 1398 students' responses to the ACiSD-Q at the start of the school year (RQ1). We then describe changes in their responses across two different moments $(n=633)$, i.e. at the beginning (M0) and end (M1) of one school year (RQ2).

\subsection{Research question 1: To what extent does early adolescents' ACiSD differ with the class group they belong to?}

After controlling for gender and educational level, $11 \%$ of variance in ACiSD (ICC $=0.111$ ) was attributable to the classroom ( $s d$ between class groups $=0.178, s d$ within class groups $=0.506$ ). In line with Lee et al. (2019) and Olsson et al. (2019), girls significantly scored slightly higher than boys as did primary school students in comparison to secondary regarding overall ACiSD as well as all subconstructs.

As shown in Table 2, our evidence suggested that at subconstruct level classrooms affected conceptual knowledge of actions for sustainable development most $(13.8 \%$, sd 
Table 2 Estimates of fixed effects and variance estimates for base model and after controlling for gender and educational level (primary, secondary) with by class group explained variance in ACiSD (ICC)

Controlling for gender and level (primary, secondary)

\begin{tabular}{|c|c|c|c|c|c|c|c|}
\hline & \multicolumn{2}{|c|}{ Fixed effects } & \multicolumn{5}{|c|}{ Variance estimates } \\
\hline & Intercept & SE & $\begin{array}{l}\text { Between } \\
\text { class } \\
\text { groups }\end{array}$ & SD & Residual & SD & ICC \\
\hline ACiSD parameter estimate & $3.912 * * *$ & 0.031 & 0.032 & 0.178 & 0.256 & 0.506 & 0.111 \\
\hline $\begin{array}{l}\text { Conceptual knowledge Parameter } \\
\text { estimate }\end{array}$ & $4.024 * * *$ & 0.033 & 0.042 & 0.205 & 0.263 & 0.513 & 0.138 \\
\hline Willingness parameter estimate & $3.885 * * *$ & 0.034 & 0.036 & 0.191 & 0.351 & 0.592 & 0.094 \\
\hline Self-efficacy parameter estimate & $3.821 * * *$ & 0.034 & 0.038 & 0.194 & 0.317 & 0.563 & 0.106 \\
\hline Capacity expectations parameter estimate & $3.771 * * *$ & 0.034 & 0.029 & 0.170 & 0.377 & 0.614 & 0.072 \\
\hline Outcome expectancy parameter estimate & $3.862 * * *$ & 0.041 & 0.063 & 0.252 & 0.384 & 0.620 & 0.142 \\
\hline
\end{tabular}

5-point Likert answer scales $(1=\mathrm{I}$ totally disagree; $3=\mathrm{I}$ do not agree and do not disagree; $5=\mathrm{I}$ totally agree)

Note: $* * *=$ significant at level $p<0.001$; SE standard error; SD standard deviation; ICC intraclass correlation coefficient

between groups $=0.205$, $s d$ within groups $=0.513)$, followed by self-efficacy $(10.6 \%$, $s d$ between groups $=0.194$, $s d$ within groups $=0.563$ ). The smallest effect of classrooms was found with willingness $(9.4 \%, s d$ between groups $=0.191$, $s d$ within groups $=0.592)$. Notably, both the smallest and largest portions of by class group explained variance were found within the self-efficacy subconstructs capacity expectations $(7.2 \%, s d$ between groups $=0.170, s d$ within groups $=0.614)$ and outcome expectancy $(14.2 \%$, sd between groups $=0.252, s d$ within groups $=0.620$ ) .

In sum, our evidence showed that the classroom level affected both overall ACiSD (11\% of variance attributable to classrooms) and its subconstructs conceptual knowledge of actions for sustainable development, willingness to contribute to such actions, capacity expectations, and outcome expectancy, with between 7.2 and $14.2 \%$ of variance explained by the classroom level. Self-efficacy subconstructs capacity expectations and outcome expectancy were affected by the classroom level least (7.2\%) and most (14.2\%), respectively.

\subsection{Research question 2: To what extent do changes in early adolescent students' ACiSD during a school year depend on the class group they belong to?}

We compared two models (likelihood ratio tests). In the first model we allowed change (from MM0 to MM1) to differ between individuals. The second model additionally allowed differences in change between class groups. The latter more complex model significantly fitted our data best for ACiSD as well as for all its subconstructs (see Table 3 for an overview).

As given in Table 4, results indicated a statistically significant positive relationship between time and ACiSD (+0.086) after controlling for gender and educational level. This means that scores increased over time $(p<0.001)$. Class groups that started with a lower mean ACiSD score showed a larger increase than those that had scored higher at 
Table 3 Overview of Likelihood ratio tests (models 1 only allow for differences in variance of change between individuals; models 2 allow for both differences in variance of change between individuals and between class groups)

\begin{tabular}{lllllllll}
\hline Construct & Model & $d f$ & AIC & BIC & $\begin{array}{l}\text { Log- likeli- } \\
\text { hood }\end{array}$ & Test & Likelihood ratio & $p$ \\
\hline ACiSD & 1 & 10 & 1444.935 & 1495.911 & -712.4677 & 1 vs 2 & 17.19757 & 0.0002 \\
& 2 & 12 & 1431.738 & 1492.908 & -703.8689 & & & \\
Conceptual & 1 & 10 & 1692.157 & 1743.458 & -836.0785 & 1 vs 2 & 10.23517 & 0.006 \\
$\quad$ knowledge & 2 & 12 & 1685.922 & 1747.483 & -830.9609 & & & \\
Willingness & 1 & 10 & 1980.349 & 2031.634 & -980.1745 & 1 vs 2 & 20.83986 & $<0.0001$ \\
& 2 & 12 & 1963.509 & 2025.051 & -969.7546 & & & \\
Self-efficacy & 1 & 10 & 1740.178 & 1791.235 & -860.0888 & 1 vs 2 & 11.96733 & 0.0025 \\
& 2 & 12 & 1732.210 & 1793.480 & -854.1051 & & & \\
Capacity expecta- & 1 & 10 & 1988.039 & 2039.236 & -984.0196 & 1 vs 2 & 15.11576 & 0.0005 \\
tions & 2 & 12 & 1976.924 & 2038.359 & -976.4618 & & & \\
Outcome expec- & 1 & 10 & 2147.137 & 2198.334 & -1063.569 & 1 vs 2 & 16.93622 & 0.0002 \\
tancy & 2 & 12 & 2134.201 & 2195.637 & -1055.101 & & & \\
\hline
\end{tabular}

M0 (correlation of $s d \mathrm{M} 0$ and M1 $=-0.677$ ). This was also the case for individual students (correlation of $s d \mathrm{M} 0$ and $\mathrm{M} 1=-0.440$ ). In sum, both individual students and class groups showed higher ACiSD scores at the end of the school year. Moreover, those who scored lower at the beginning of the school year gained more than those who already scored higher initially.

We found similar results for subconstructs conceptual knowledge, willingness (albeit significant at the $p<0.05$ level and non-significant, respectively), and overall self-efficacy $(p<0.001)$. Mean scores significantly increased with 0.067 for conceptual knowledge and 0.128 for overall self-efficacy. Correlations between standard deviations at M0 and M1 for class groups were -0.756 for conceptual knowledge and -0.612 for overall self-efficacy, while those between individual students showed values of -0.476 for conceptual knowledge and -0.240 for overall self-efficacy.

Finally, both self-efficacy subconstructs, i.e. capacity expectations $(+0.102)$ and outcome expectancy $(+0.173)$, showed a statistically significant increase at M1 $(p<0.01)$ compared to M0. Again, we found negative correlations between standard deviations at M0 and M1 for class groups ( -0.689 for capacity expectations, -0.695 for outcome expectancy) as well as between individual students ( -0.542 for capacity expectations, -0.381 for outcome expectancy).

Compared to the beginning of the school year (M0), results indicate increases in overall ACiSD and all its subconstructs by the end of the school year (M1), which are statistically significant except for subconstruct willingness. At class group (Fig. 4a) as well as at individual student level (Fig. 4b), correlations between scores at M0 and changes between M1 and M0 were negative as shown in Fig. $4 \mathrm{a}$ and $\mathrm{b}$ for overall ACiSD. This means that scores of class groups and individual students that showed lower values at M0 increased more than those who scored higher at the beginning of the school year. 
㤩递

$\stackrel{\circ}{ \pm}$

횽

范

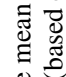

巳

造

造

:

离

:

胥



产.

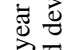

원

을

莀

苟

吾

元

:

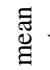

里

总

ज्ञ

离.

흥

焉市

空

要

进

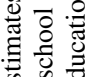

के के

屯

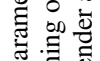

光寻总

๖

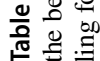

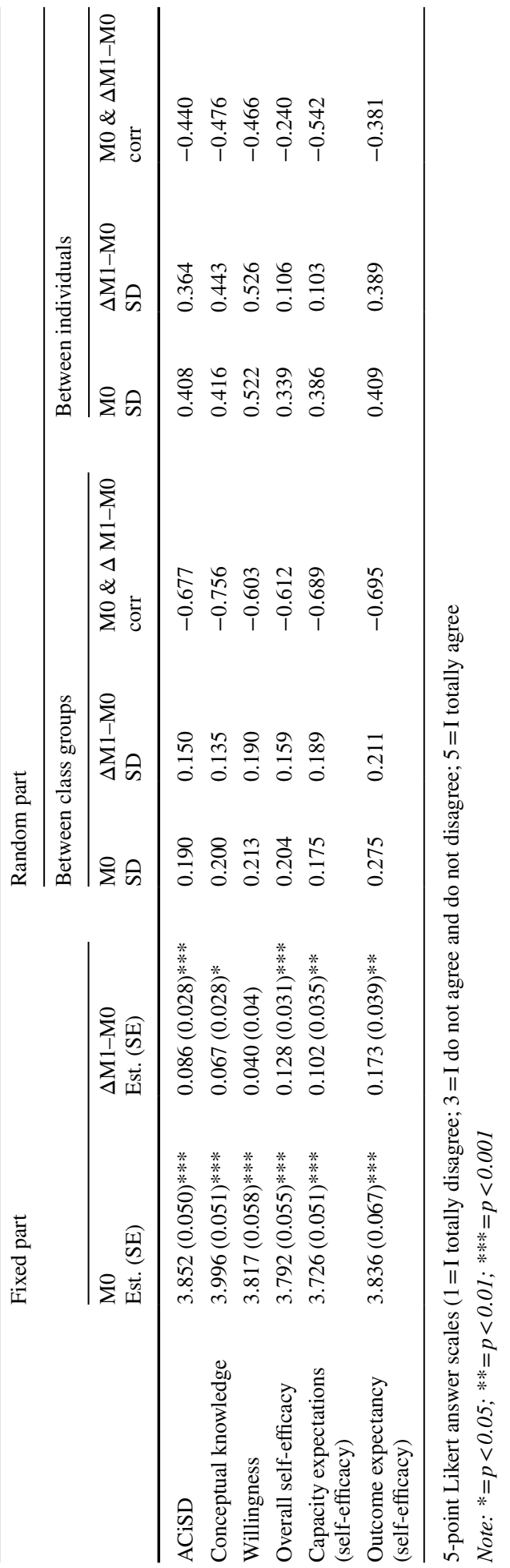


(a)

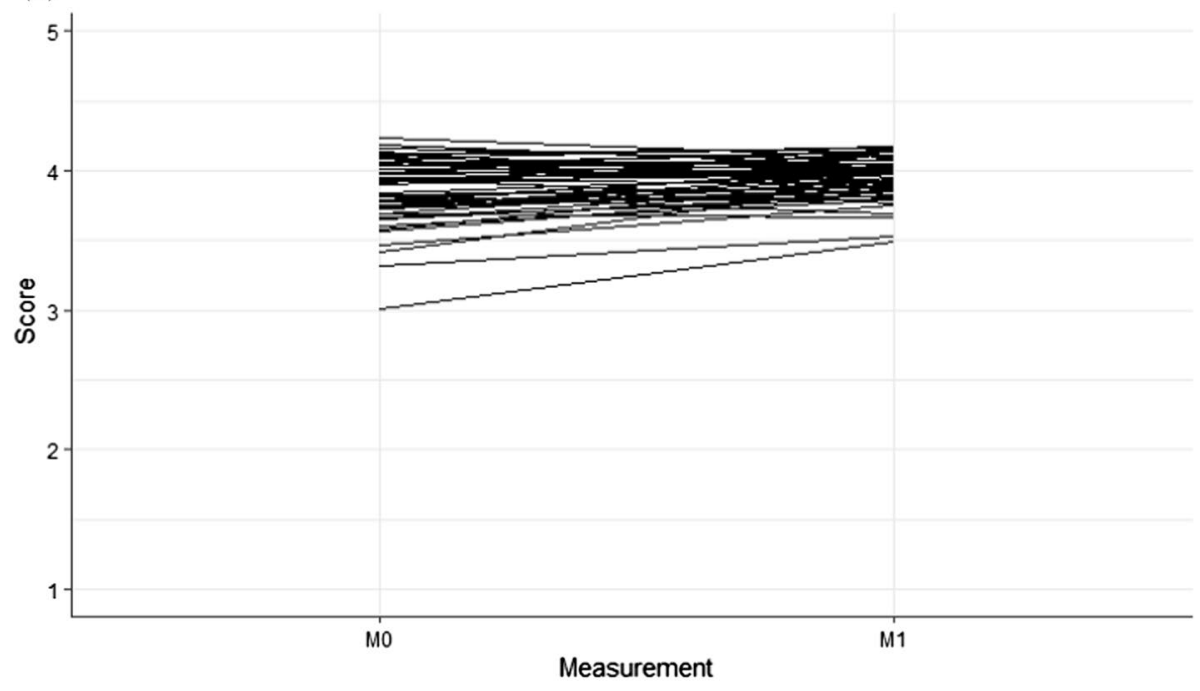

(b)

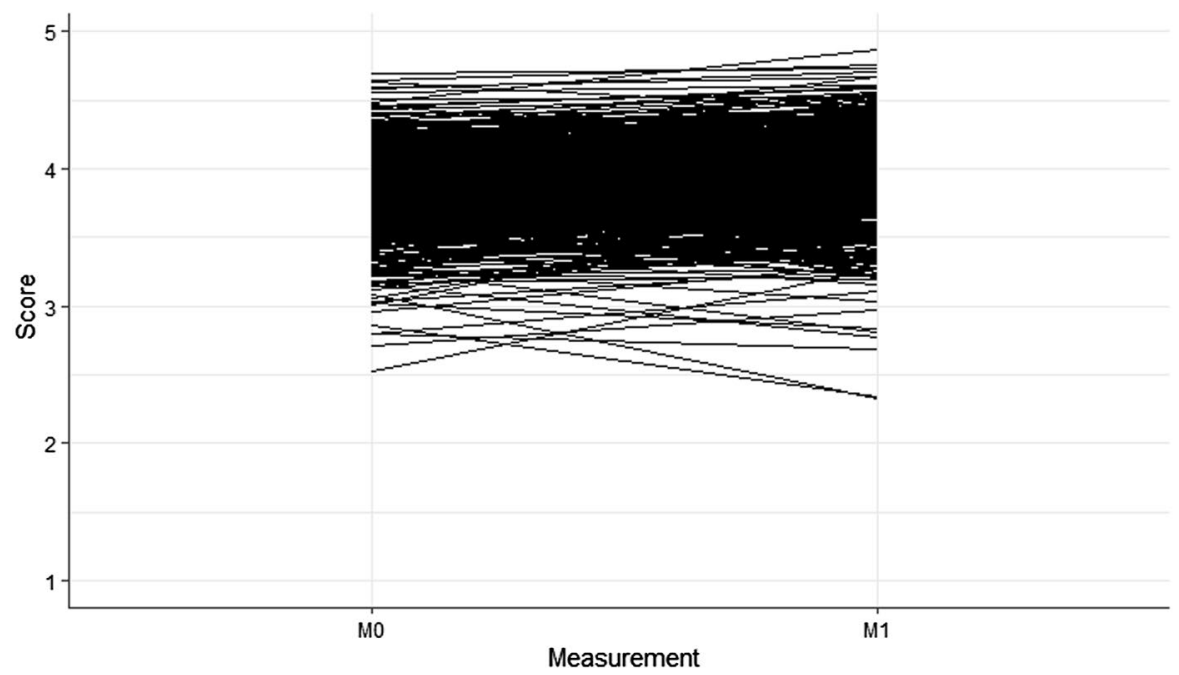

Fig. 4 a Graphic representations of mean estimated ACiSD scores per class group. b Graphic representations of mean estimated ACiSD scores per student (random sample of 100 students) 


\section{Conclusion and discussion}

Both the research community (e.g. Javadinejad, Dara, \& Jafary, 2020; Kerich, 2020; Oo, Zin, \& Kyi, 2020) and policy makers (e.g. European Commission, 2019; United Nations, 2019) underscore the importance of sustainable development in overcoming the challenges set by issues such as climate change. Education is thought to be key in preparing future generations for facing this issue (Amézaga et al., 2021; Minelgaitė \& Liobikienė, 2021; Sekhar \& Raina, 2021). However, before educational efforts can be monitored, research should ask whether formal education in schools and classrooms affects students' action competence regarding sustainable development (ACiSD). The current study contributed by revealing that the classroom level matters to changes in ACiSD within 10- to 14-year-old students. Analyses of our data showed that $11 \%$ of variance in ACiSD could be attributed to the classroom level. After controlling for gender and educational level, our evidence further suggests that classrooms affect especially conceptual knowledge of actions for sustainable development and self-efficacy subconstruct outcome expectancy as it explained 13.8 and $14.2 \%$ of variance, respectively. Interestingly, self-efficacy subconstructs capacity expectations (7.2\%) and outcome expectancy (14.2\%) showed smallest and highest proportions of variance attributable to the classroom level. As trust in one's own capability to solve sustainable development issues enhances behavioural change (Bandura, 1977; Chawla, 2009; Wu \& Mweemba, 2010), teaching programmes would do well to enhance students' capacity expectations. Making students aware of sustainable development issues (Wu \& Mweemba, 2010) and giving them opportunities for experiencing their own capacity to make a difference could support them in feeling more confident in their power as change agents (Bandura, 1977). Actions directed towards contributing to sustainable development are complex, as they have to take into account different, often even conflicting, interests. Therefore partnerships are necessary for tackling SD issues (United Nations, 2015). Consequently, students need to learn how to cooperate (UNESCO, 2017) in order to take collective action (Clark, 2016). Moreover, individual actions may be felt to be inadequate in view of SD issues' global scale. Class groups provide ample opportunities for experiencing collective action among peers. Moreover, collective action enhances participants' self-efficacy regarding the group's and their individual competence for making change (Chawla \& Flanders Cushing, 2007). We hypothesise that experiences of collective action may encourage the individual student involved, which may explain the large proportion of explained variance in outcome expectancy, as this refers to students' confidence in a positive outcome of their action. Further research may want to verify these assumptions. Close to $10 \%$ of variance in motivational aspects such as willingness (9.4\%) and overall self-efficacy (10.6\%) was attributable to the classroom level. These proportions of explained variance in overall ACiSD and its subconstructs are in line with explained variance in learning outcomes in cognitive domains ranging between 10 and 20\% (Muijs, 2006). Attitudes towards the environment in the family homes have also been found to influence behaviours regarding sustainable development (Corral-Verdugo et al., 2019). Consequently, given that classrooms typically explain more variance in domains such as mathematics as compared to language teaching, the proportion of explained variance in ACiSD and its subconstructs found in the current study appears to be in line with the previous literature regarding mathematics, science, and language outcomes. When looking into how class groups' ACiSD and 
subconstructs evolved, we can conclude that all class groups' ACiSD, conceptual knowledge, willingness, capacity expectations, and outcome expectancy increased on average after one school year. However, not all groups and students evolved to the same extent. Groups and individual students with lower levels at the start of the school year, showed a more substantial average increase than did those that started the school year at a higher level. This means that those class groups and students who showed less action competence at the beginning of the school year, benefitted most from a year of classroom experience. This may encourage schools to take on the challenge of empowering students for taking action for sustainable development, while seeking connection with attitudes regarding sustainable development the students bring to the classroom from their homes. However, ceiling effects may partly explain this finding, as class groups and students who already scored high to start with had less room for positive change towards the end of the school year.

Further effectiveness research should look into effects of more specific aspects of the 'black box' called classroom on students' development of ACiSD. An educational approach thought to foster ACiSD is education for sustainable development (ESD). Alongside pluralism, which allows different perspectives in discussions regarding possible actions for sustainable development, and an orientation towards action, a third feature of ESD is holism (Stables \& Scott, 2002). This expresses the aim to equip students with the capacity for acknowledging that sustainable development issues consist of interrelated environmental, social, economic, and political aspects that occur in the past, present, and future, as well as in local, regional, and global contexts (United Nations, 2015). Consequently, ESD should combine three features, i.e. holism (Stables $\&$ Scott, 2002), pluralism (Öhman, 2008), and an orientation towards action (Biesta, 2009a, 2009b; Chawla, 2009; Mogensen \& Schnack, 2010; Sinakou, Boeve-de Pauw, Donche, \& Van Petegem, 2019). As this was not the aim of the current study, our data do not allow to attribute the increases in overall ACiSD and its subconstructs to a specific educational approach, such as ESD. Classrooms are an environment in which not only teachers and students, but also students amongst themselves, may influence each other (Scheerens, 2016). Nevertheless, ESD features such as holism, pluralism, and action-orientedness are theoretically expected to enhance students' action competence (Breiting et al., 2009; Ke et al., 2020; Öhman, 2008; Sinakou, Boeve-de Pauw, Donche, $\&$ Van Petegem, 2019; Stables \& Scott, 2002). With our study we paved the way for further teacher effectiveness research that may want to find evidence for and look into the details of this theoretical connection.

Regardless of the contribution the current research made to the field, it was also constrained by limitations that open venues for further research. Firstly, all participants attended schools that took part in the VALIES project (Valorising Integrated and ActionOriented Education for Sustainable Development at School), which aimed to enhance ESD implementation. Consequently, variance in ACiSD and its subconstructs may have been underestimated in the current study. Future research may want to look into differences between schools or class groups in which ESD was not explicitly implemented. Secondly, our data did not allow reaching any conclusions regarding causal relationships between the implementation of ESD or its features of holism, pluralism, and action-orientedness with students' increased ACiSD or its subconcepts. It would be interesting to find out if, and what ESD features affect which ACiSD aspects and how this happens. Mixed-method and 
qualitative studies might shed light on these questions. Qualitative methods, such as class observation, semi-structured interviews and focus groups, would allow to dig deeper into why and how certain teaching approaches help students develop ACiSD, while quantitative methods would shed light on the extent to which these findings go beyond individual contexts and experiences.

Thirdly, as the current study only measured students' ACiSD at two moments, i.e. at the beginning and end of school year 2019-2020, our results may show a more linear development of ACiSD than is realistic. Longitudinal research with more measurements across a longer period of time would allow for a more nuanced insight. Finally, as our evidence suggests that, contrary to the average student and class group, individual students as well as individual classes sometimes showed a negative evolution (see Fig. 4a and b), these would be interesting cases to compare to students and class groups that showed increases in ACiSD and its subconstructs in subsequent qualitative research.

In conclusion, we are confident that this study has contributed to the field by revealing that what happens in classrooms contributes to changes in early adolescents' ACiSD and its subconstructs. Regardless of the challenges this poses to schools and teachers, our evidence has paved the way for broadening the scope of teacher effectiveness research beyond isolated basic mathematics, science, and language skills as was called for in the fields of policy (UNESCO, 2017) and academia (Muijs et al., 2014, 2016). The path has now been paved for researching whether and how teachers' efforts to implement ESD may be fruitful for supporting students in developing action competence, conceptual knowledge of action possibilities, willingness to contribute, capacity expectations, and outcome expectancy regarding sustainable development issues. Thus, the current study constitutes a first step towards monitoring educational efforts that aim to prepare young adolescents for facing future sustainability challenges.

\section{Appendix}

See Tables 5 and 6. 


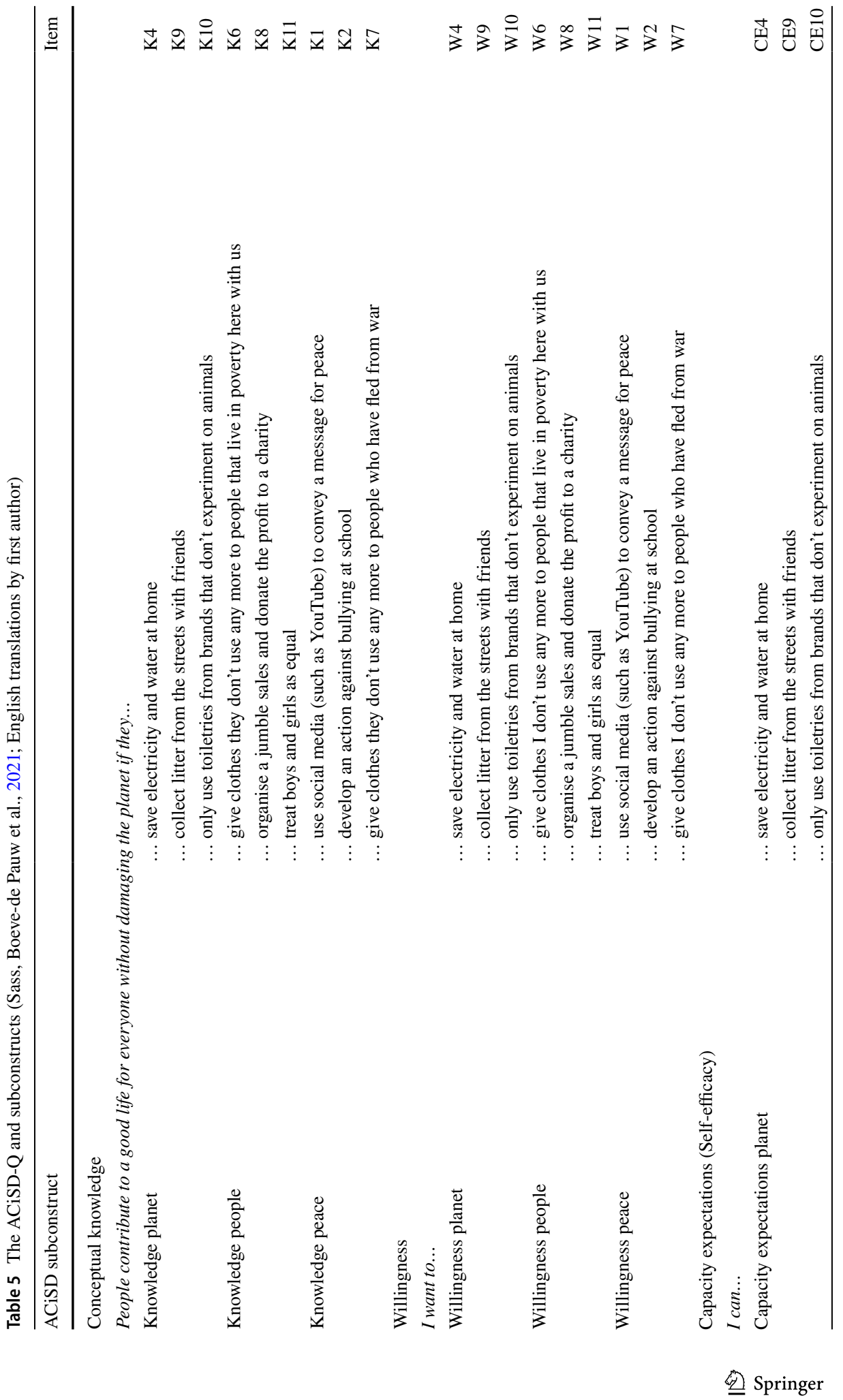




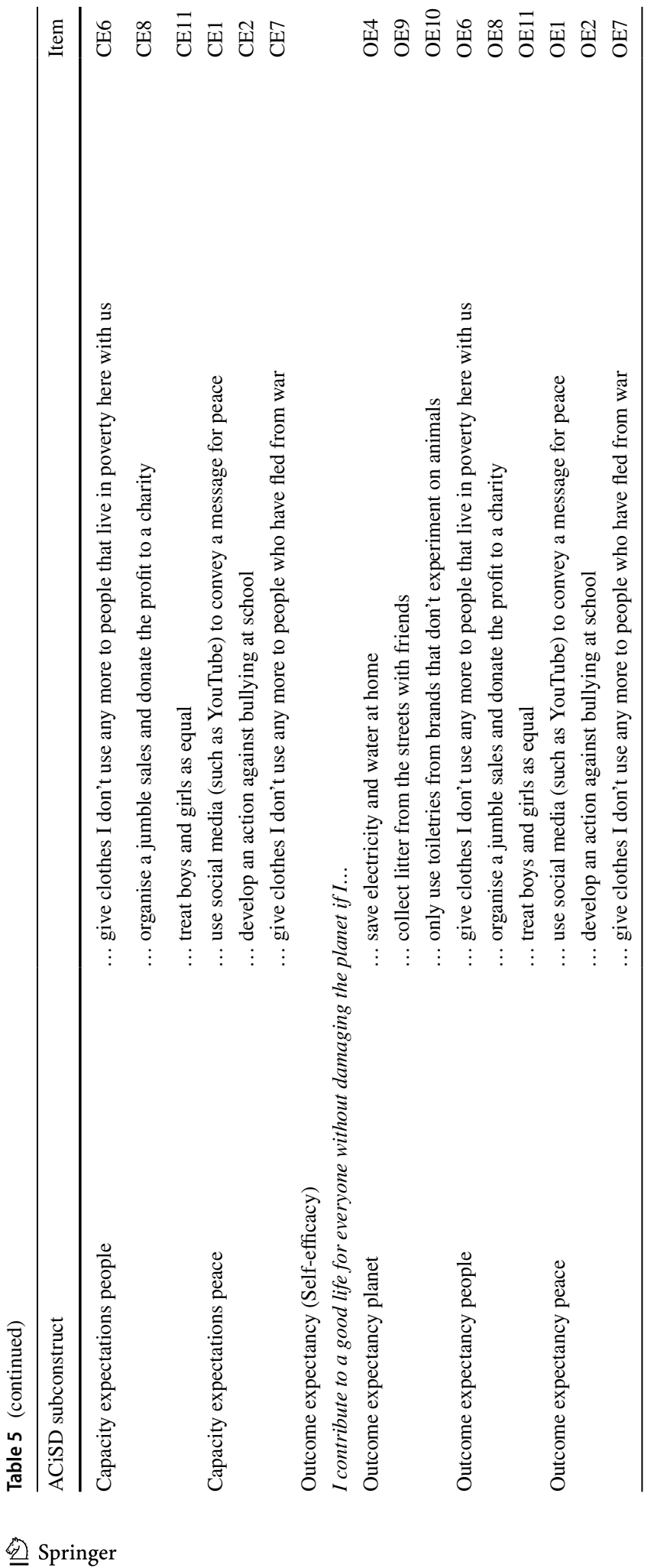


Table 6 Descriptive statistics (means and standard deviations) of ACiSD and subconstructs, overall, by gender and educational level (primary and secondary)

\begin{tabular}{|c|c|c|c|c|c|c|c|c|c|c|}
\hline \multirow[t]{3}{*}{ (Sub)construct } & \multirow{2}{*}{\multicolumn{2}{|c|}{ Overall }} & \multicolumn{4}{|l|}{ Gender } & \multicolumn{4}{|c|}{ Educational level } \\
\hline & & & \multicolumn{2}{|l|}{ Male } & \multicolumn{2}{|l|}{ Female } & \multicolumn{2}{|c|}{ Primary } & \multicolumn{2}{|c|}{ Secondary } \\
\hline & Means & SD & Means & SD & Means & SD & Means & SD & Means & SD \\
\hline ACiSD & 3.95 & 0.56 & 3.82 & 0.61 & 4.11 & 0.44 & 4.02 & 0.51 & 3.73 & 0.66 \\
\hline Conceptual knowledge & 4.07 & 0.57 & 3.95 & 0.62 & 4.21 & 0.45 & 4.13 & 0.51 & 3.87 & 0.69 \\
\hline Willingness & 3.93 & 0.66 & 3.76 & 0.72 & 4.13 & 0.51 & 4.03 & 0.59 & 3.62 & 0.75 \\
\hline Self-efficacy & 3.86 & 0.61 & 3.76 & 0.65 & 3.98 & 0.51 & 3.91 & 0.57 & 3.69 & 0.70 \\
\hline Capacity expectations & 3.83 & 0.64 & 3.72 & 0.70 & 3.96 & 0.54 & 3.87 & 0.61 & 3.69 & 0.74 \\
\hline Outcome expectancy & 3.89 & 0.68 & 3.79 & 0.72 & 4.02 & 0.59 & 3.95 & 0.64 & 3.70 & 0.75 \\
\hline
\end{tabular}

SD standard deviation

Acknowledgements The authors would like to thank all participating schools and respondents for their constructive cooperation and feedback. We are also grateful for the help of all working students and colleagues involved in the data collections and digitalisation of the paper questionnaires. Finally, we are grateful for the encouraging comments received from the journal's editor and anonymous reviewers.

Funding This study is part of the VALIES project and is funded by the Flanders Research Foundation (FWO) under grant agreement S010317N within the Strategic Basic Research programme.

\section{Declarations}

Ethics approval The ethical guidelines and advice of the researchers' institution were observed (the University of Antwerp Ethics Committee for Social and Human Sciences, approval number SHW_18_25).

\section{References}

Amézaga, T. R. W., Camarena, J. L., Figueroa, R. C., \& Realivazquez, K. A. G. (2021). Measuring sustainable development knowledge, attitudes, and behaviors: Evidence from university students in Mexico. Environment, Development and Sustainability, 1-24,. https://doi.org/10.1007/s10668-021-01467-0

Amoah, A., \& Addoah, T. (2021). Does environmental knowledge drive pro-environmental behaviour in developing countries? Evidence from households in Ghana. Environment, Development and Sustainability, 23(2), 2719-2738. https://doi.org/10.1007/s10668-020-00698-x

Arı, E., \& Yılmaz, V. (2017). Effects of environmental illiteracy and environmental awareness among middle school students on environmental behavior. Environment, Development and Sustainability, 19(5), 1779-1793. https://doi.org/10.1007/s10668-016-9826-3

Bandura, A. (1977). Self-efficacy: Toward a unifying theory of behavioral change. Psychological Review, 84(2), 191-215. https://doi.org/10.1037/0033-295X.84.2.191

Bates, D., Mächler, M., Bolker, B. M., \& Walker, S. C. (2015). R Package lme4 (version 1.1-23) [computer software]. RStudio.

Biesta, G. (2009a). What kind of citizenship for European higher education? Beyond the competent active citizen. European Educational Research Journal, 8(2), 146-158. https://doi.org/10.2304/eerj.2009.8. 2.146

Biesta, G. (2009b). Good education in an age of measurement: On the need to reconnect with the question of purpose in education. Educational Assessment, Evaluation and Accountability, 21(1), 33-46. https://doi.org/10.1007/s11092-008-9064-9 
Breiting, S., Hedegaard, K., Mogensen, F., Nielsen, K., \& Schnack, K. (2009). Action competence, conflicting interests and environmental education - the MUVIN programme. Research Programme for Environmental and Health Education, DPU (Danish School of Education).

Breiting, S., \& Mogensen, F. (1999). Action competence and environmental education. Cambridge Journal of Education, 29(3), 349-353. https://doi.org/10.1080/0305764990290305

Chapman, C., Muijs, D., Reynolds, D., Sammons, P., \& Teddlie, C. (Eds.). (2016a). The Routledge International Handbook of Educational Effectiveness and Improvement. Routledge.

Chapman, C., Reynolds, D., Muijs, D., Sammons, P., Stringfield, S., \& Teddlie, C. (2016). Educational effectiveness and improvement research and practice: The emergence of the discipline. In C. Chapman, D. Muijs, D. Reynolds, P. Sammons, \& C. Teddlie (Eds.), The Routledge International Handbook of Educational Effectiveness and Improvement (pp. 1-24). Routledge.

Chawla, L. (2009). Growing up green: Becoming an agent of care for the natural world. The Journal of Developmental Processes, 41(1), 6-23.

Chawla, L., \& Flanders Cushing, D. (2007). Education for strategic environmental behavior. Environmental Education Research, 13(4), 437-452. https://doi.org/10.1080/13504620701581539

Clark, C. R. (2016). Collective action competence: An asset to campus sustainability. International Journal of Sustainability in Higher Education, 17(4), 559-578. https://doi.org/10.1108/IJSHE-04-2015-0073

European Commission (2019). Communication from the Commission to the European Parliament, the European Council, the Council, the European Economic and Social Committee and the Committee of the Regions - The European Green Deal (COM(2019) 640 final). European Commission. https://eur-lex. europa.eu/legal-content/EN/TXT/PDF/?uri=CELEX:52019DC0640\&from=EN

Corral-Verdugo, V., Lucas, M. Y., Tapia-Fonllem, C., \& Ortiz-Valdez, A. (2019). Situational factors driving climate change mitigation behaviors: The key role of pro-environmental family. Environment, Development and Sustainability, 22, 7269-7285. https://doi.org/10.1007/s10668-019-00496-0

Hattie, J. (2009). Visible Learning. A synthesis of over 800 meta-analyses relating to achievement. London and New York: Routledge.

Hox, J. J., Moerbeek, M., \& van de Schoot, R. (2017). Multilevel Analysis: Techniques and Applications (3rd ed.). Routledge.

Javadinejad, S., Dara, R., Jafary, F. (2020). Climate change scenarios and effects on snow-melt runoff. Civil Engineering Journal, 6(9), 1715-1725. https://doi.org/10.28991/cej-2020-03091577

Jensen, B. B. (2000). Health knowledge and health education in the democratic health-promoting school. Health Education, 100(4), 146-154. https://doi.org/10.1108/09654280010330900

Jensen, B. B., \& Schnack, K. (2006). The action competence approach in environmental education. Environmental Education Research, 12(3-4), 471-486. https://doi.org/10.1080/13504620600943053

Ke, L., Sadler, T. D., Zangori, L., \& Friedrichsen, P. J. (2020). Students' perceptions of socio-scientific issue-based learning and their appropriation of epistemic tools for systems thinking. International Journal of Science Education, 42(8), 1339-1361. https://doi.org/10.1080/09500693.2020.1759843

Kelly, A., \& Clarke, P. (2016). The challenges of globalisation and the new policy paradigms for educational effectiveness and improvement research. In C. Chapman, D. Muijs, D. Reynolds, P. Sammons, \& C. Teddlie (Eds.), The Routledge International Handbook of Educational Effectiveness and Improvement (pp. 365-379). Routledge.

Kerich, E.C. (2020). Households drinking water sources and treatment methods options in a regional irrigation scheme. Journal of Human, Earth, and Future, 1(1), 10-19. https://doi.org/10.28991/ HEF-2020-01-01-02

Kuznetsova, A., Brockhoff, P. B., \& Christensen, R. H. B. (2017). R Package lmerTest (Version 3.1-2) [computer software]. RStudio.

Lee, Y. C., Grace, M., Rietdijk, W., \& Lui, Y. C. (2019). A cross-cultural, cross-age, and cross-gender study of Hong Kong and UK secondary students' decision making about a biological conservation issue. International Journal of Science Education, 41(18), 2696-2715. https://doi.org/10.1080/09500693. 2019.1693662

Milfont, T. L. (2012). The interplay between knowledge, perceived efficacy, and concern about global warming and climate change: A one-year longitudinal study. Risk Analysis: An International Journal, 32(6), 1003-1020. https://doi.org/10.1111/j.1539-6924.2012.01800.x

Minelgaitė, A., \& Liobikienė, G. (2021). Changes in pro-environmental behaviour and its determinants during long-term period in a transition country as Lithuania. Environment, Development and Sustainability, 1-17,. https://doi.org/10.1007/s10668-021-01329-9

Mogensen, F., \& Schnack, K. (2010). The action competence approach and the 'new' discourses of education for sustainable development, competence and quality criteria. Environmental Education Research, 16(1), 59-74. https://doi.org/10.1080/13504620903504032 
Muijs, D. (2006). Measuring teacher effectiveness: Some methodological reflections. Educational Research and Evaluation, 12(1), 53-74. https://doi.org/10.1080/13803610500392236

Muijs, D., Kyriakides, L., van der Werf, G., Creemers, B., Timperley, H., \& Earl, L. (2014). State of the art - teacher effectiveness and professional learning. School Effectiveness and School Improvement, 25(2), 231-256. https://doi.org/10.1080/09243453.2014.885451

Muijs, D., Reynolds, D., \& Kyriakides, L. (2016). The scientific properties of teacher effects/effective teaching processes. In C. Chapman, D. Muijs, D. Reynolds, P. Sammons, \& C. Teddlie (Eds.), The Routledge International Handbook of Educational Effectiveness and Improvement (pp. 100-123). Routledge.

Öhman, J. (2008). Environmental ethics and democratic responsibility - A pluralistic approach to ESD. In J. Öhman (Ed.), Values and democracy in education for sustainable development: Contributions from Swedish research (pp. 17-32). Liber.

Olsson, D., Gericke, N., Boeve-de Pauw, J., Berglund, T., \& Chang, T. (2019). Green schools in Taiwan-Effects on student sustainability consciousness. Global Environmental Change, 54, 184-194. https://doi.org/10.1016/j.gloenvcha.2018.11.011

Oo, H., Zin, W., \& Kyi, C. (2020). Analysis of streamflow response to changing climate conditions using SWAT Model. Civil Engineering Journal. 6(2), 194-209. https://doi.org/10.28991/cej-2020-03091 464

Ottander, K., \& Simon, S. (2021). Learning democratic participation? Meaning-making in discussion of socioscientific issues in science education. International Journal of Science Education, 43(12), 1895-1925. https://doi.org/10.1080/09500693.2021.1946200

Pinheiro, J., Bates, D., DebRoy, S., Sarkar, D., \& R Core Team. (2014). R Package nlme (version 3.1150) [computer software]. RStudio.

Rabe-Hesketh, S., \& Skrondal, A. (2012). Multilevel and Longitudinal Modeling using Stata (3rd ed.). STATA Press.

Reynolds, D., Sammons, P., De Fraine, B., Van Damme, J., Townsend, T., Teddlie, C., \& Stringfield, S. (2014). Educational effectiveness research (EER): A state-of-the-art review. School Effectiveness and School Improvement, 25(2), 197-230. https://doi.org/10.1080/09243453.2014.885450

Reynolds, D., Chapman, C., Clarke, P., Muijs, D., Sammons, P., \& Teddlie, C. (2016). The future of educational effectiveness and improvement research, and some suggestions and speculations. In C. Chapman, D. Muijs, D. Reynolds, P. Sammons, \& C. Teddlie (Eds.), The Routledge International Handbook of Educational Effectiveness and Improvement (pp. 408-439). Routledge.

Reynolds, D., Teddlie, C., Chapman, C., \& Stringfield, S. (2016b). Effective school processes. In C. Chapman, D. Muijs, D. Reynolds, P. Sammons, \& C. Teddlie (Eds.), The Routledge International Handbook of Educational Effectiveness and Improvement (pp. 77-99). Routledge.

Sammons, P., Davis, S., \& Gray, J. (2016). Methodological and scientific properties of school effectiveness research. Exploring the underpinnings, evolution, and future directions of the field. In C. Chapman, D. Muijs, D. Reynolds, P. Sammons, \& C. Teddlie (Eds.), The Routledge International Handbook of Educational Effectiveness and Improvement (pp. 25-76). London and New York: Routledge.

Sass, W., Boeve-de Pauw, J., Olsson, D., Gericke, N., De Maeyer, S., \& Van Petegem, P. (2020). Redefining action competence: The case of sustainable development. The Journal of Environmental Education, 51(4), 292-305. https://doi.org/10.1080/00958964.2020.1765132

Sass, W., Boeve-de Pauw, J., De Maeyer, S., \& Van Petegem, P. (2021): Development and validation of an instrument for measuring action competence in sustainable development within early adolescents: the action competence in sustainable development questionnaire (ACiSD-Q). Environmental Education Research, 27(9), 1284-1304. https://doi.org/10.1080/13504622.2021.1888887

Sass, W., Quintelier, A., Boeve-de Pauw, J., De Maeyer, S., Gericke, N., \& Van Petegem, P. (2021). Actions for sustainable development through young students' eyes. Environmental Education Research, 27(2), 234-253. https://doi.org/10.1080/13504622.2020.1842331

Scheerens, J. (2016). Educational Effectiveness and Ineffectiveness. A Critical Review of the Knowledge Base. Springer.

Scott, J. (2008). Children as Respondents. In P. Christiansen \& A. James (Eds.), Research with Children: Perspectives and Practices (pp. 87-108). Routledge.

Sekhar, C., \& Raina, R. (2021). Towards more sustainable future: Assessment of sustainability literacy among the future managers in India. Environment, Development and Sustainability, 1-27,. https:// doi.org/10.1007/s10668-021-01316-0

Sinakou, E., Donche, V., Boeve-de Pauw, J., \& Van Van Petegem, P. (2019). Designing powerful learning environments in education for sustainable development: A conceptual framework. Sustainability, 11(21), 5994. https://doi.org/10.3390/su11215994 
Smetana, J. G., Campione-Barr, N., \& Metzger, A. (2006). Adolescent development in interpersonal and societal contexts. Annual Review of Psychology, 57, 255-284. https://doi.org/10.1146/annurev. psych.57.102904.190124

Stables, A., \& Scott, W. (2002). The Quest for Holism in Education for Sustainable Development. Environmental Education Research, 8(1), 53-60. https://doi.org/10.1080/13504620120109655

Townsend, T., MacBeath, J., \& Bogotch, I. (2016). Critical and alternative perspectives on educational effectiveness and improvement research. In C. Chapman, D. Muijs, D. Reynolds, P. Sammons, \& C. Teddlie (Eds.), The Routledge International Handbook of Educational Effectiveness and Improvement (pp. 380-407). Routledge.

UNESCO (2017). Education for Sustainable Development Goals: Learning Objectives. UNESCO. https:// unesdoc.unesco.org/ark:/48223/pf0000247444

United Nations. (2015). Transforming Our World: The 2030 Agenda for Sustainable Development (A/ RES/70/1). United Nations. https://www.un.org/en/development/desa/population/migration/generalass embly/docs/globalcompact/A_RES_70_1_E.pdf

United Nations. (2019). Report of the Secretary-General on the 2019 Climate Action Summit and the Way Forward in 2020. United Nations. https://www.un.org/sites/un2.un.org/files/cas_report_11_dec_0.pdf

Varela-Losada, M., Vega-Marcote, P., Pérez-Rodríguez, U., \& Álvarez-Lires, M. (2016). Going to action? A literature review on educational proposals in formal Environmental Education. Environmental Education Research, 22(3), 390-421. https://doi.org/10.1080/13504622.2015.1101751

Wickham, H. (2016). R Package ggplot2 (version 3.3.2) [computer software]. RStudio.

$\mathrm{Wu}, \mathrm{H}$., \& Mweemba, L. (2010). Environmental self-efficacy, attitude and behavior among small scale farmers in Zambia. Environment. Development and Sustainability, 12(5), 727-744. https://doi.org/10. 1007/s10668-009-9221-4

Yilmaz, V., \& Can, Y. (2020). Impact of knowledge, concern and awareness about global warming and global climatic change on environmental behavior. Environment, Development and Sustainability, 22(7), 6245-6260. https://doi.org/10.1007/s10668-019-00475-5

Publisher's Note Springer Nature remains neutral with regard to jurisdictional claims in published maps and institutional affiliations.

\section{Authors and Affiliations}

\section{Wanda Sass $^{1}$ (D) . Sven De Maeyer ${ }^{1}$ (D) Jelle Boeve-de Pauw ${ }^{1}$ (D) $\cdot$ Peter Van Petegem $^{1}$ (D)}

Sven De Maeyer

sven.demaeyer@uantwerpen.be

Jelle Boeve-de Pauw

Jelle.Boeve-dePauw@uantwerpen.be

Peter Van Petegem

peter.vanpetegem@uantwerpen.be

1 Department of Training and Education Sciences, Faculty of Social Sciences, Research Unit Edubron, University of Antwerp, Sint-Jacobstraat 2, 2000 Antwerp, Belgium 